\title{
IAU COMMISSION 46: ASTRONOMY EDUCATIONAL MATERIAL
}

\author{
M. Gerbaldi \\ Institut d'Astrophysique, 98 bis Bd Arago, 75014 Paris, France and \\ Université de Paris XI, Centre d'Orsay, Lab. d'Astronomie Bât 470, 91405 Orsay, \\ France
}

During the IAU Assembly in Prague (1967), Commission 46 on the Teaching of Astronomy decided to prepare a world-wide list of available material suitable for astronomy education at various levels and as in many languages as possible.

The first list was published in 1970 by E. Müller, under the title: "Astronomy Educational Material." Since then, in order to keep the list up to date, an "Addendum" has been edited every three years.

Each Addendum is subdivided into three parts:

part A: material in the English language

part B: material in Slavic languages

part C: material in all languages with the exception of English and Slavic.

These Addenda are sent to everyone on the mailing list of the Commission 46 Newsletter. To receive the Newsletter, write to Prof. Leo Houziaux, Institut d'Astrophysique, 5 Ave. de Cointe, B-4200 Cointe-Ougrée, Liege, Belgium.

Table 1 presents the number of books listed in Addendum $\mathrm{C}$ according to language. The very high figures in Chinese (period 1982-1985) and in Romanian (1985-1988) resulted from the fact that these lists were then published for the first time and contained materials since 1949 .

From a quick look at this table, we can surely conclude that there are very strong differences among the different countries. The main question is: are the lists exhaustive or a selection of the best items? In any case, is such an Addendum C useful in all languages?

From personal experience, I know that editing and publishing such Astronomy Educational Material consumes more and more manpower and becomes more and more costly. It became necessary to rediscuss the goal of such a document.

A decision about the future of the AEM was made during the IAU General Assembly held at Baltimore (U.S.A.) in August 1988. It is obvious that the real need is for lists of selected items at different levels in a few languages; English, French, and Spanish were selected. Such lists published by Commission 46 should be effective for astronomically developing countries. 
Table 1. Number of books listed in each Addendum $\mathrm{C}$ according to their language.

\begin{tabular}{|c|c|c|c|c|c|}
\hline & 1973-76 & 1976-79 & $1979-1982$ & $1982-85$ & $1985-88$ \\
\hline Dutch (Holland) & 3 & 6 & 1 & & \\
\hline French (France) & 8 & 95 & 88 & 211 & 117 \\
\hline German (F.R.G.) & 9 & 12 & 24 & 16 & 112 \\
\hline Greek & 33 & 21 & 26 & & 17 \\
\hline Hungarian & 6 & 8 & 8 & 11 & 19 \\
\hline Indonesian & 5 & 4 & 6 & & \\
\hline Italian & 15 & 48 & 20 & 15 & 8 \\
\hline Japanese & 48 & 38 & 45 & 32 & 20 \\
\hline Norwegian & 2 & 2 & & 4 & - \\
\hline Spanish (Spain) & 1 & 31 & 59 & 19 & 22 \\
\hline Swedish & 14 & 30 & 25 & & 6 \\
\hline Danish & & 8 & & & \\
\hline Finnish & & 7 & 14 & 12 & 9 \\
\hline Afrikaner & & & 1 & & 3 \\
\hline Portuguese (Portugal) & & & 3 & 6 & 1 \\
\hline Chinese (Rep. Populaire) & & & & 424 & 73 \\
\hline French (Belgium) & & & & 23 & 2 \\
\hline French (Canada) & & & & 15 & 1 \\
\hline French (Switzerland) & & & & 4 & \\
\hline German (Austria) & & & & 6 & 2 \\
\hline German (G.D.R.) & & & & 9 & 5 \\
\hline Indi (India) & & & & 3 & \\
\hline Spanish (Mexico) & & & & 4 & 1 \\
\hline Arabic (Egypt) & & & & & 1 \\
\hline Dutch (Belgium) & & & & & 4 \\
\hline Hebrew & & & & & 2 \\
\hline Malaysian & & & & & 1 \\
\hline Nigerian & & & & & - \\
\hline Portuguese (Brazil) & & & & & 10 \\
\hline Romanian & & & & & 322 \\
\hline Spanish (Columbia) & & & & & 2 \\
\hline Spanish (Venezuela) & & & & & 1 \\
\hline Thai & & & & & 83 \\
\hline
\end{tabular}

